\title{
IN VITRO STUDIES ON THE PROTECTIVE EFFECT OF TANNIC ACID OF U87 CELLS INDUCED BY BETA-AMYLOID
}

\section{Guluzar Ozbolat ${ }^{1}$ Ares Alizade ${ }^{2}$}

\author{
${ }^{1}$ Sinop University, Faculty of Health Science, Sinop, Turkey. \\ ${ }^{2}$ Mustafa Kemal University, Faculty of Veterinary, Department of Pharmacology, Hatay, Turkey
}

\author{
Address for Correspondence: Guluzar Ozbolat, E-mail: guluzarozbolat@gmail.com \\ Received: 03.09.2021; Accepted: 13.09.2021; Available Online Date: 20.09.2021 \\ (C) Copyright 2021 by Dokuz Eylül University, Institute of Health Sciences - Available online at https://dergipark.org.tr/en/pub/jbachs
}

Cite this article as: Ozbolat G, Alizade A. In Vitro Studies on The Protective Effect of Tannic Acid of U87 Cells Induced by Beta-Amyloid. J Basic Clin Health Sci 2021; 3: 213- 217.

\begin{abstract}
Background: While the prevalence of Alzheimer's disease continues to increase throughout the twentieth century, the cause and pathology of the disease are not well understood and scientists are seeking treatments for the disease. Tannic acid can be used effectively to treat Alzheimer's disease and seems to be one of the alternative therapeutic strategies in medicine. In this study, we aimed to investigate the effects of tannic acid on the U87 (human astrocytoma cell line) treated with amyloid-beta $(A \beta)$, which is the Alzheimer's disease $(A D)$ model cell line.

Materials and Methods: In the study; three groups were formed as the control group, the $A \beta$ group, and the $A \beta+$ tannic acid group obtained by adding tannic acid to the $A \beta$ group. Firstly, the cytotoxic potential of TA in U87 cells was investigated by the colorimetric MTT (3-4,5-dimethyl-thiazolyl-2,5 diphenyltetrazolium bromide) test. To determine the antioxidant status in the cell line treated with tannic acid, to examine the effects of total oxidant status (TOS), superoxide dismutase (SOD), total antioxidant status (TAS) and catalase (CAT) activities, were measured by the ELISA method.

Results: In our study, the viability and proliferation of the cell decreased in U87 cells treated with amyloidB compared to the control group, but tannic acid increased cell viability and proliferation when compared with the group treated with amyloid-B. When compared to the control group, the TAS, SOD, and CAT levels were significantly decreased in the U87 cell line exposed to A $\beta$; TOS levels were found to increase significantly.
\end{abstract}

Conclusions: In in vitro experiments, we determined that tannic acid has a protective effect by increasing antioxidant parameters in the amyloid beta-induced cell line.

Keywords: Tannic acid, Amyloid-beta, U87, Alzheimer's

\section{INTRODUCTION}

Alzheimer's disease $(A D)$ is a chronic disease characterized by insidious cognitive impairment. Alzheimer's disease takes place among the most common causes of dementia $(1,2,3)$. No approved drugs can either revert or arrest the progression of AD. Effective treatments are greatly needed. The amyloid-cascade hypothesis has, since its introduction in 1991, provided the dominant framework for understanding the pathogenesis of $A D$. $A \beta$ peptides are at the root of the pathology of Alzheimer's disease (AD), one of the devastating diseases of an increasingly aging society $(4,5)$. 
The $37-43$ amino acid amyloid $\beta$-peptide $(A \beta)$ is produced by the proteolytic cleavage of a membrane protein called $\beta$-amyloid precursor protein (APP). The most prominent targets for therapeutic intervention include the inhibition of APP (6-9).Age-related memory impairments have been depicted to be associated with decreased antioxidant mechanisms in the brain and plasma. The interaction of $A \beta 42$ plaques with free radicals and the oxidative stress as a result of it may play a pivotal role in $A D$ pathogenesis $(10,11)$.

Tannic acid has antimutagenic and antioxidant activities. Tannic acid (TA) is a naturally occurring plant-derived polyphenol found in several plants. TA has been well studied for its antimutagenic, anticarcinogenic and antioxidant activities. Notably, the high content of polyphenols present in some plants may positively influence the pathology of $A D$ $(12-15)$. It is thought that tannic acid could be utilized effectively for the treatment of Alzheimer's Disease and we anticipated that it could be evaluated among alternative treatment strategies in the field of medicine.

\section{MATERIALS AND METHODS}

\section{Working Groups}

Control group: $50 \mu \mathrm{l}$ of saline was added to the medium of differentiated U87 cells and incubated for 48 hours. Dimethyl Sulfoxide (DMSO) was added to the medium for 24 hours in the incubator.

$A \beta$ group: $A \beta 1-42$ was added to the medium of the differentiated U87 cells at a concentration of $5 \mu \mathrm{M}$ and incubated for 48 hours. After, DMSO was added to the medium of the cells.

$\mathbf{A} \beta+$ tannic acid group: The differentiated U87 cells were added to the culture medium at a final concentration of $5 \mu \mathrm{M}, 48$ hours after $A \beta 1-42$ application. $300 \mu \mathrm{mol} / \mathrm{L}$ TA was added and the mixture was incubated.

Cytotoxicity: At the end of the 48 hours, U87 cell line cells were transferred to 96 well plates with $100 \mu \mathrm{L}$ of cell suspension per well and $10 \mu \mathrm{L}$ of MTT solution was added. The MTT solution was prepared by dissolving it in PBS as $5 \mathrm{mg} / \mathrm{mL}$ and transferring it to a bottle with sterile filtration. Afterward, $100 \mu \mathrm{L}$ of DMSO was added to each well and the well was kept in a $\mathrm{CO} 2$ incubator at $37^{\circ} \mathrm{C}$ for 10 minutes at $37^{\circ} \mathrm{C}$ to dissolve the formazan crystals formed by MTT. Their cytotoxicity levels were calculated employing the following formula.

1- (the absorbance of the test pad - the absorbance of the control pad / the absorbance of the test pad) $x$ 100 the concentration with $50 \%$ cytotoxic effect relative to the control was accepted as the cytotoxic dose.

ELISA (Enzyme-Linked Immunosorbent Assay) Test: To evaluate the antioxidant status in the cell line treated with TA, SOD, CAT, TOS, and TAS activities were measured based on ELIZA method to examine its effect on the apoptosis process. Experimental protocols of ELIZA kits vary for each kit.

\section{RESULTS \\ MTT Test}

The effect of TA human brain cell line U87 (glioblastoma astrocytoma) on cell viability and proliferation was also investigated. Following the application of $A \beta 1-42$, the number of viable cells decreased in all the groups except for the control group ( $p<0.05)$. After the application of the TA on U87 cells, there was a significant statistical increase in the number of cells in the $A \beta+$ TA group $(p<0.05)$ (Fig.1). According to these results, it was determined that the TA increased cell survival in the in vitro $A H$ model.

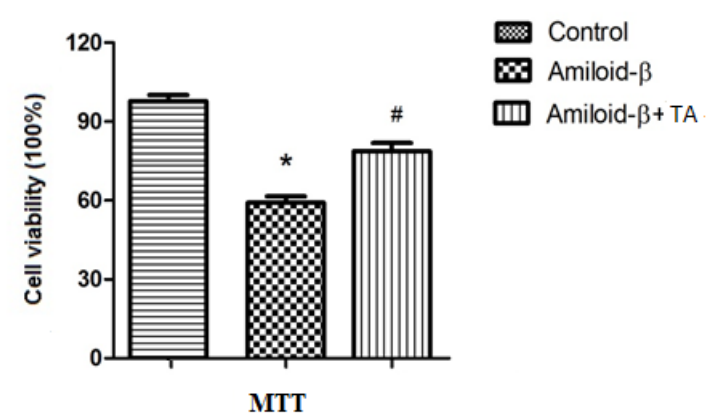

Figure 1. Cell viability of the groups with TA added versus $A \beta 1-42$ application.

\section{CAT Activity}

Our findings indicated that CAT enzyme level $(\mathrm{pg} / \mathrm{ml})$ significantly decreased after $A \beta 1-42$ administration in all the groups except for the control group $(p<0.05)$. We observed a significant statistical increase in CAT enzyme level in the $A \beta+$ TA group after the TA was applied on the U87 cell ( $p<0.05$ ) (Figure 2). Moreover, the results implied that the TA triggers the antioxidant enzyme mechanism. 


\section{SOD Activity}

The application of amyloid-B to the cells significantly decreased the SOD ( $U / \mathrm{mg}$ protein) enzyme level in all the groups except for the control group $(p<0.05)$. The SOD enzyme level increased significantly in the $A \beta+T A$ group after Timoquinone was applied on the U87 cell $(p<0.05)$ (Figure 2$)$. It has been determined that TA triggers the antioxidant enzyme mechanism.

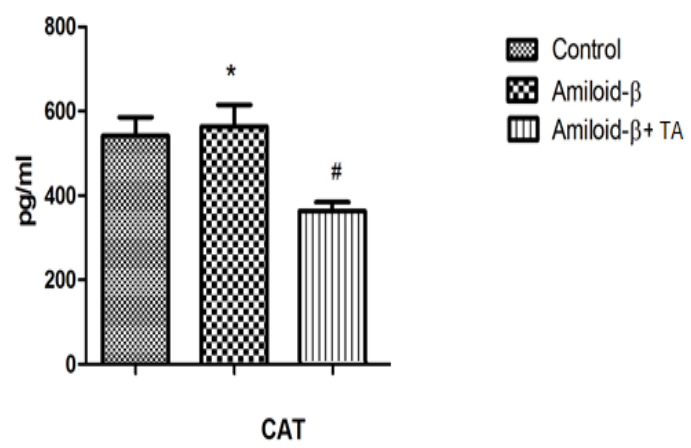

Figure 2. CAT enzyme $(\mathrm{pg} / \mathrm{ml}$ ) level values in in vitro $\mathrm{AH}$ model cell lines.

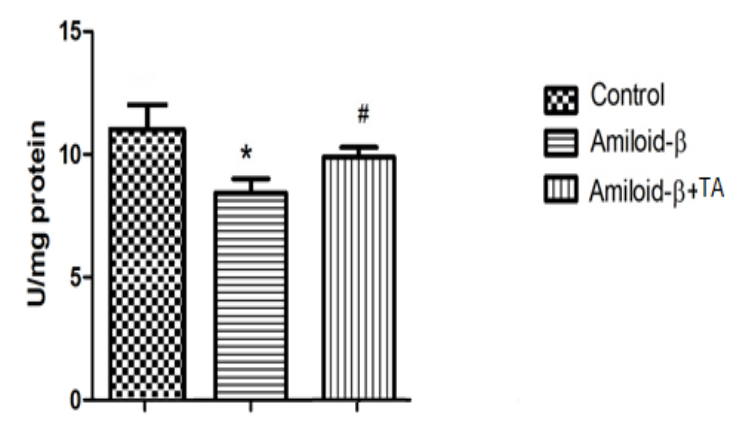

SOD

Figure 3. SOD enzyme $(\mathrm{U} / \mathrm{mg})$ level values in the in vitro $\mathrm{AH}$ model cell lines

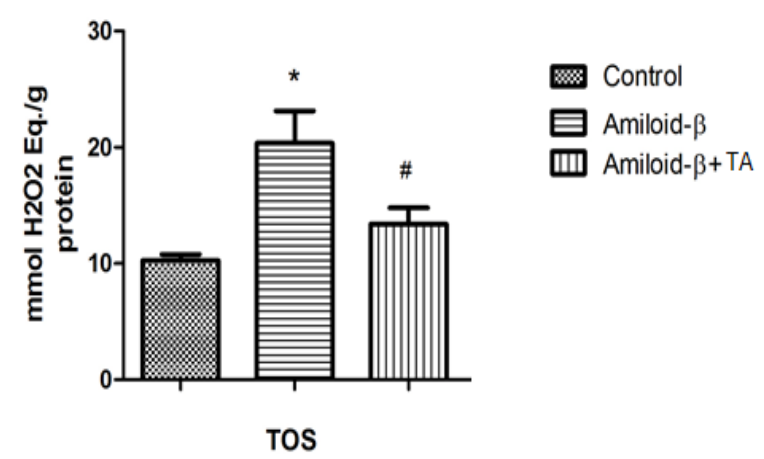

Figure 4. TOS level values in the in vitro $\mathrm{AH}$ model cell lines

\section{TOS Activity}

Our findings indicated that TOS enzyme level significantly decreased after $A \beta 1-42$ administration in all the groups except for the control group $(p<0.05)$. We observed a significant statistical increase in TOS enzyme level in the $A \beta+$ TA group after TA was applied on the U87 cell $(p<0.05)$ (Figure 4$)$.

\section{TAS Activity}

Our findings indicated that TOS enzyme level significantly increased after $A \beta 1-42$ administration in all the groups except for the control group $(p<0.05)$. We observed a significant statistical decrease in TOS enzyme level in the $A \beta+$ TA group after TA was applied on the U87 cell $(p<0.05)$ (Figure 3$)$.

\section{DISCUSSION}

Alzheimer's disease (AD) is characterized by the accumulation in the brain of extracellular amyloid $\beta$ $(A \beta)$ plaques. $A D$ is one of the leading causes of dementia affecting millions of people worldwide.Oxidative stress is the most important factor in the pathogenesis of Alzheimer's and occurs when reactive oxygen and nitrogen species increase, or the antioxidant defense system decreases. TAC represents DNA oxidation and provides data on the interpretation of the pathogenesis and treatment of AD (16-18).

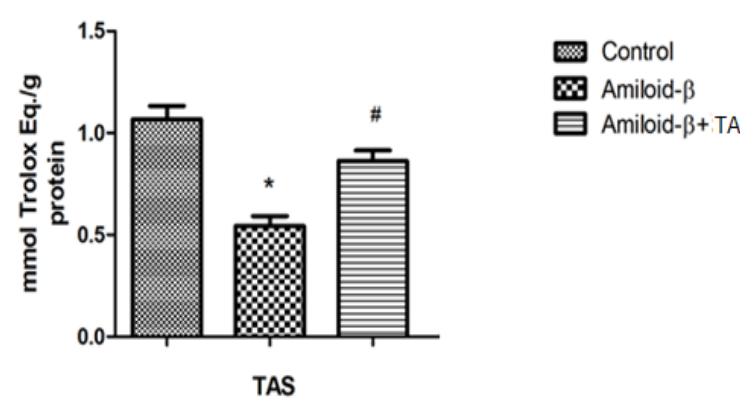

Figure 5. TAS level values in the in vitro $\mathrm{AH}$ model cell lines

In our study, we analyzed TOS and TAS values to evaluate the total oxidant and antioxidant effect. We observed a significant statistical decrease in TOS and TAS enzyme level in the A $\beta+$ TA group after TA was applied to the U87 cell. Arslan et al. showed TAC level was significantly increased after farnesene exposure also; there was a significant difference in TOS levels compare to $\beta$-amyloid applied cell culture $(19,20)$. 
In some studies, a difference has been reported between $A D$ and controls in terms of SOD, yet it was not statistically significant. On the contrary, other studies have shown that the SOD level increased significantly. According to the obtained data herein, amyloid-B administration significantly reduced SOD activity on human brain cell line U87 (glioblastoma astrocytoma) cells compared to the controls. We found that the TA application significantly augmented this decrease and implied an antioxidant effect. In the studies in the literature, different results were obtained with the change of SOD expression and activity in patients with Alzheimer's Disease. On top of the findings showing a significant decrease in SOD activity in the hippocampus, there are researches indicating no differences in SOD activity compared to controls. It has been determined that TA triggers the antioxidant enzyme mechanism (21-23).

In addition, the increase in the level of antioxidant enzyme CAT in the in vitro AD group compared to the control and its decrease with TA application, along with the increase in the free radicals in $A D$, is indicative of an increase in enzymatic antioxidant activation in order to eliminate the toxic effects of these radicals. The oxidative stress induced by $A \beta$ and the antioxidant defense mechanism associated with them are accepted as basic mechanisms in the etiology and pathogenesis of Alzheimer's. As a result of the disruption of the balance between antioxidant and oxidant systems, free radicals emerge. It protects the cell against oxidative stress by eliminating these radicals, which are SOD, GSH-Px, CAT; they are endogenous enzymes involved in the antioxidant defense mechanism (23-26).

U87 supports the antioxidant defense system in the Alzheimer's cell line model, significantly increasing the levels of TAS, CAT and SOD while decreasing the level of TOS. TA represented antioxidant activity and decreased neurodegeneration due to apoptosis. Therefore, the treatment with TA could be suggested as a novel therapeutic approach to the prevention and symptomatic treatment of Alzheimer's.

Author contributions: All authors discussed the results and contributed to the final manuscript. G.Ö. and A.A.carried out the experiment. G.Ö and A. A. wrote the manuscript.

Funding statement: All funding of the study was supported by the authors.

\section{REFERENCES}

1. Lista $S$, Hampel H. Synaptic degeneration and neurogranin in the pathophysiology of
Alzheimer's disease. Expert Rev Neurother. 2017; 17(1): 47-57.

2. Yiannopoulou KG. Papageorgiou SG. Current and Future Treatments in Alzheimer Disease: An Update. Journal of Central Nervous System Disease 2020; 12: 1-12.

3. Murata $S$, Ono R, Sugimoto $T$, Toba K, Sakurai T. Functional Decline and Body Composition Change in Older Adults With Alzheimer Disease: A Retrospective Cohort Study at a Japanese Memory Clinic. Alzheimer Dis Assoc Disord. 2021; 35(1): 36-43.

4. Kant RVD, Goldstein LSB. Ossenkoppele R. Amyloid- $\beta$-independent regulators of tau pathology in Alzheimer disease. Nature Reviews Neuroscience; 2020; 21: 21-35.

5. Hardy, J. \& Selkoe, D. J. The amyloid hypothesis of Alzheimer's disease: progress and problems on the road to therapeutics. Science 2002; 297, 353-356.

6. Zheng $\mathrm{H}, \mathrm{Koo} \mathrm{EH}$. Biology and pathophysiology of the amyloid precursor protein. Mol Neurodegener 2011; 6: 27.

7. Talib WH, Zarga, MH, Mahasneh AN. Antiproliferative, Antimicrobial and Apoptosis Inducing Effects of Compounds Isolated from Inula viscosa. Molecules 2012; 17: 3291-3303.

8. Dinamarca MC, Cerpa W, Garrido J, Hancke JL, Inestrosa NC. Hyperforinprevents betaamyloidneurotoxicity and spatial memory impairments by disaggregation of Alzheimer's amyloidbeta-deposits. MolPsychiatry 2006; 11: 1032-1048.

9. A Nordberg. Mechanisms behind the neuroprotective actions of cholinesterase inhibitors in Alzheimer disease Alzheimer Dis Assoc Disord 2006; 20: S12-S18

10. Dinamarca MC, Cerpa W, Garrido J, Hancke JL, Inestrosa NC. Hyperforinprevents betaamyloidneurotoxicity and spatial memory impairments by disaggregation of Alzheimer's amyloidbeta-deposits. MolPsychiatry, 2006, 11(11):1032--1048.

11. Talib WH, Zarga MH, Mahasneh AN. Antiproliferative, Antimicrobial and Apoptosis Inducing Effects of Compounds Isolated from Inulaviscosa. MoleculeS 2012; 17: 3291-3303

12. S. Aswathy Aromal and D. Philip, "Facile one-pot synthesis of gold nanoparticles using tannic acid and its application in catalysis," Physica E, vol. 44, no. 7-8, pp. 1692-1696, 2012. 
13. Braidy N, Jugder BE, Poljak A, Jayasena $T$, Nabavi SM, Sachdev P, Grant R. Molecular Targets of Tannic Acid in Alzheimer's Disease. Curr Alzheimer Res. 2017; 14(8): 861-869.

14. Gonsette R. Neurodegeneration in multiple sclerosis: the role of oxidative stress and excitotoxicity. J Neurol Sci 2008; 274: 48-53

15. Mattioli R, Francioso A, d'Erme, Trovato $M$, Mancini P, Piacentini L, Casale AM, Wessjohann L, Gazzino R, Costantino P, Mosca L (2019) Antiinflammatory activity of a Polyphenolic extract from Arabidopsis thaliana in in vitro and in vivo models of Alzheimer's disease. Int $\mathrm{J}$ Mol Sci 20:708-727Janı KP.

16. Serrano-Pozo, A., M. P. Frosch, E. Masliah and B. T. Hyman. Neuropathological alterations in Alzheimer disease. 2011; Cold Spring Harb Perspect Med 1(1): a006189.

17. Clark IA and Vissel B: Amyloid $\beta$ : One of three danger-associated molecules that are secondary inducers of the proinflammatory cytokines that mediate Alzheimer's disease. $\mathrm{Br} J$ Pharmacol 2015; 172: 3714-3727.

18. Castellani RJ, Rolston RK, Smith MA. Alzheimer disease. Dis Mon 2010; 56(9): 484-546.

19. Arikanoglu A. Akil E. Varol S. Yucel Y. Yuksel H. et al., Relationship of cognitive performance with prolidase and oxidative stress in Alzheimer disease. Neurol Sci 2013; 34(12):2117-21.

20. Arslan ME. Türkez H. Mardinoğlu A. In vitro neuroprotective effects of farnesene sesquiterpene on alzheimer's disease model of differentiated neuroblastoma cell line, International Journal of Neuroscience, 2020.

21. Gsell W, Conrad R, Hickethier M, Sofic E, Frolich L, Wichart I, Jellinger K, Moll G, Rnsmayr G, Beckmann $\mathrm{H}$ et al. Decreased Catalase Activity but Unchanged Sueroxide-Dismutase Activity in Brains of Patients with Dementia of AlzheimerTye. J Neurochem 1995, 64(3): 1216-1223

22. Kumar R. Lal N. Nemaysh V. Luthra PM. Demethoxycurcumin mediated targeting of MnSOD leading to activation of apoptotic pathway and inhibition of Akt/NF-kB survival signalling in human glioma U87 MG cells. Toxicology and Applied Pharmacology; 2018; (345):75-93.

23. Mohandas E, Rajmohan V, Raghunath $B$. Neurobiology of Alzheimer's disease. Indian journal of psychiatry,2009; 51(1): 55.54
24. Wang $P$, Luo $Q$, Qiao $H$, Ding $H$, Cao $Y$, Yu J, Liu R, Zhang Q, Zhu H, Qu L. The Neuroprotective Effects of Carvacrol on Ethanol-Induced Hippocampal Neurons Impairment via the Antioxidative and Antiapoptotic Pathways. Oxid Med Cell Longev, 2017; 2017: 4079425.

25. Oh PS. Lim KT. Blocking of intracellular ROS production by phytoglycoprotein (30 kDa) causes anti-proliferation in bisphenol A-stimulated Chang liver cells. J Appl Toxicol, 2008; 28: 749-58.

26. Park MY, Jeong YJ, Kang GC, Kim MH, Kim SH et al., Nitric oxide-induced apoptosis of human dental pulp cells is mediated by the mitochondriadependent pathway. Korean J Physiol Pharmacol 2014; 18: 25-32. 